\title{
Nirihuau: Explotación de hidrocarburos y conflicto social en las inmediaciones de Bariloche (Patagonia, Argentina)
}

Niribuau: Hydrocarbons Exploitation and Social Conflict in the Surrounding Area of Bariloche (Patagonia, Argentina)

Niribuau: exploração de hidrocarbonetos e conflito social nas imediações de Bariloche (Patagônia, Argentina)

\section{Guido Galafassi* \\ Diego Pérez Roig**}

Recibido: 5 de agosto de 2013

Aprobado: 28 de octubre de 2013

Doi: dx.doi.org/10.12804/territ30.2014.07

Para citar este artículo:

Galafassi, G. y Pérez, D. (2014). Nirihuau: explotación de hidrocarburos y conflicto social en las inmediaciones de Bariloche (Patagonia, Argentina). Territorios, 30, 147-169. doi: dx.doi.org/10.12804/territ30.2014.07

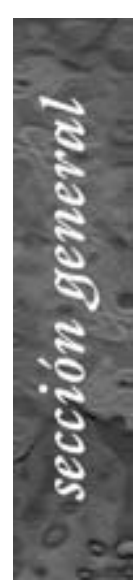

* Universidad Nacional de Quilmes-Conicet. Doctor en Antropología, director del proyecto de investigación "Acumulación, conflictos sociales y territorio en la Argentina contemporánea. Análisis de casos regionales”. Correo electrónico: ggalafassi@unq.edu.ar

** Universidad Nacional de Quilmes-Conicet. Licenciado en Ciencia Politica, estudiante de doctorado de la Universidad de Buenos Aires e integrante del $\mathrm{Ob}$ servatorio Petrolero Sur. Actualmente investiga el desarrollo de la industria bidrocarburifera en la Patagonia argentina. Correo electrónico: diegoperezroig@gmail.com 
Palabras clave Niribuau, Patagonia, hidrocarburos, conflicto social, pueblo mapuche.

Keywords

Niribuau, Patagonia, bydrocarbons, social conflict, mapuche people.

Palavras-chave

Nirihuau, Patagônia, hidrocarbonetos, conflito social, povo mapuche.

\section{territarias 30}

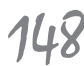

\section{RESUMEN}

En el año 2008, el gobierno de la provincia de Río Negro (Patagonia, Argentina) licitó y adjudicó a la Unión Transitoria de Empresas (UTE) YPF-Pluspetrol el área petrolera Nirihuau para trabajos de exploración y eventual explotación de hidrocarburos. La iniciativa suscitó un importante proceso de movilización social, por cuanto el bloque concesionado lindaba con el Parque Nacional Nahuel Huapi y se ubicaba dentro de la reserva de biosfera Andino Norpatagónica. Asimismo, la zona es soporte de otras actividades económicas incompatibles con el proyecto y comprende territorios ancestrales reivindicados por comunidades indígenas mapuche. En el siguiente estudio de caso analizaremos el diseño y la implementación de esta política, focalizándonos en las peculiares características del área Nirihuau y los cuestionamientos y estrategias seguidas por quienes se opusieron a la concesión. Hacia el final, pondremos este análisis en contexto, y lo relacionaremos con la situación de la industria hidrocarburífera argentina.

\section{ABSTRACT}

In 2008 the Government of the Province of Río Negro (Patagonia, Argentina) bade and awarded the area Nirihuau to a joint venture between YPF and Pluspetrol, for exploration and possible exploitation of hydrocarbons. The initiative gave rise to an important process of social protests, due to the proximity of this block with Nahuel Huapi National Park, and the fact that it was located within the Andean Northpatagonic Biosphere Reserve. Also, several economic activities which are incompatible with the project take place in the area, which comprises ancestral territories claimed by indigenous communities as well. In this case study we will analyze the design and the implementation of this public policy, focusing in the peculiar characteristics of Nirihuau area, and the questioning and the strategies followed by those who opposed to the concession. In the end, we will put this analysis in context, and we will relate it with the state of the argentine hydrocarbon industry.

\section{RESUMO}

No ano 2008 o Governo da Província de Rio Negro (Patagônia, Argentina) licitou e adjudicou à União Transitória de Empresas (UTE) YPF-Pluspetrol a área petroleira "Ñirihuau" para trabalhos de exploração em geral, e eventual exploração de hidrocarbonetos. A iniciativa suscitou um importante processo de mobilização social, por quanto o bloco de concessão limitava com o Parque Nacional Nahuel Huapi e se localizava dentro da Reserva de Biosfera Andino Norpatagônica. Igualmente, a zona é suporte de outras atividades econômicas incompatíveis com o projeto, e compreende territórios ancestrais reivindicados por comunidades indígenas mapuche. No seguinte estudo de caso analisaremos a criação e a implementação desta política, nós focalizando nas peculiares características da área "Ñirihuau", e os questionamentos e estratégias seguidas por aqueles que se opuseram à concessão. Para o final, poremos esta análise em contexto, e o relacionaremos com a situação da indústria de hidrocarbonetos argentina. 
La Patagonia, entre la acumulación originaria y la nueva sed de recursos ${ }^{* *}$

La ocupación para la colonización argentina de la región andino-patagónica estuvo fundamentalmente ligada a las campañas militares (Navarro, 1999; Bandieri, 2005). Hacia la segunda mitad del siglo XIX, la inserción más decidida del país en el mercado mundial - resultante del aumento de la demanda de materias primas y alimentos-, tuvo como correlato una rápida ampliación de sus fronteras, y un fenomenal proceso de concentración de la tierra.

La utilización de las zonas más fértiles de la Pampa húmeda para la cría de ganado vacuno y el cultivo de cereales, determinó el traslado de la producción de lana a los territorios de la Patagonia, a la sazón marginales, pero igualmente aptos para la ganadería ovina. Así fue cómo, con la denominada Conquista del desierto, se cerró un ciclo de décadas de ampliación de la propiedad latifundiaria en Argentina. Si bien, en líneas generales, el proceso no estuvo signado por un despojo que produjera toda la mano de obra libre necesaria para el funcionamiento del modo capitalista de producción, sí constituyó un monopolio sobre la tierra que definiría el marco estructural en el que posteriormente se integrarían los trabajadores provenientes del exterior. "Se trata de un verdadero proceso de acumulación originaria de capital, que por lo demás sólo alcanza su 'frontera' definitiva mediante la expropiación brutal de los territorios indígenas" (Cueva, 1986, p. 75).
Detrás de la publicitada justificación ideológica de 'superar la barbarie' para instalar definitivamente 'la civilización y el progreso', se escondió el objetivo concreto y palpable de conquistar nuevas tierras para dedicarlas a la producción. Estado y capital se avinieron para emprender la tarea 'civilizatoria', a partir de un contundente proceso de apropiación privada de los recursos y el territorio, cuyo "agente de ocupación, si lo hubo, fue el ganado y no el hombre" (Bandieri, 2005, p. 128). Así, mientras la meseta se construyó a partir de inmensos latifundios para la producción lanar, la región andina fue parcialmente visualizada y valorizada como recurso paisajístico que permitía completar el modelo cultural europeo adoptado por las clases dominantes locales. En el otro extremo, las poblaciones indígenas remanentes luego del genocidio de la 'conquista del desierto' quedaron confinadas a pequeños reductos en litigio permanente hasta la actualidad.

Con el correr del siglo xx, el componente de población occidental se fue diversificando por el aporte de un gran número de inmigrantes extranjeros y de contingentes provenientes de los principales centros urbanos, particularmente del Área Metropolitana de Buenos Aires. De esta manera, el perfil oligárquico original se fue matizando - especialmente en las zonas urbanas-, y se produjo un crecimiento de los sectores medios a la par de la masificación del turismo.

En nuestros días, toda la Patagonia es concebida - y tratada - como una región con un enorme potencial de explotación.
*** El presente artículo se enmarca en un proyecto de investigación financiado por la Universidad Nacional de Quilmes (Buenos Aires, Argentina), cuyo objetivo es analizar críticamente la relación entre los cambios en el modo de acumulación de capital -con sus procesos de desarrollo asociados-y los conflictos sociales que vienen ocurriendo en la Argentina en las últimas décadas. Parte de las investigaciones que abonan a dicho proyecto, hacen foco especialmente en la expresión territorial de aquella relación, incorporando las diversas expresiones espaciales de los procesos de desarrollo y conflicto social. La hipótesis general del proyecto es que los conflictos sociales se correlacionan dialécticamente con el modo de acumulación begemónico a nivel nacional, y que a su vez presentan especificidades de acuerdo a las variantes regionales que adopta el modo de desarrollo y la trama de sujetos $y$ clases sociales presentes.

territarias 30 149

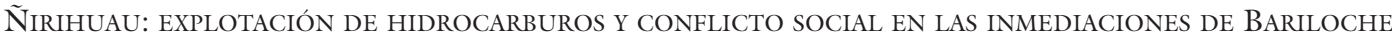


Valga como ejemplo la edición de enero de 2004 de la revista National Geographic, que la destaca como un "espacio abierto a la ocupación internacional", cuyo territorio y recursos aún "esperan al afortunado": cerca de $230000 \mathrm{~km}^{2}$ de cuencas con recursos hídricos y $4000 \mathrm{~km}^{2}$ de superficie sobre el área de los hielos continentales y glaciares, que configuran una de las mayores reservas de agua dulce del planeta; recursos hidrocarburíferos y minerales todavía no del todo explorados; y muy buenas perspectivas para el desarrollo de formas alternativas de energía (Worrall, 2004). Así las cosas, no es sorprendente que en los últimos años la región se haya convertido en sinónimo de conflictos por la apropiación de la tierra y sus recursos.

En este artículo nos concentraremos en la región de la cuenca del Nirihuau ubicada entre las provincias de Río Negro y Chubut, en la que tanto organizaciones de pueblos originarios como distintos movimientos sociales y ONG urbanas se vieron involucrados en procesos de movilización y resistencia. El reclamo por el derecho a la tierra mapuche, un nuevo proyecto de extracción de hidrocarburos y la existencia de un parque nacional fueron los ingredientes particulares alrededor de los cuales se fueron sucediendo y superponiendo los conflictos. En este estudio de caso nos enfocaremos particularmente en el generado por la licitación y adjudicación del área petrolera Nirihuau, llevada adelante por el gobierno rionegrino en 2008.

\section{Oro negro en Ñirihuau}

Río Negro es una de las provincias patagónicas que participan de la extracción de hidrocarburos. Si bien el comienzo de la actividad en lo que hoy es su territorio se remonta a las primeras décadas del siglo XX, recién en 1960 la empresa estatal Yacimientos Petrolíferos Fiscales (YPF) logró perforar el primer pozo técnica y económicamente viable en la localidad de Catriel, dentro de la cuenca Neuquina, la única productiva del subsuelo provincial hasta el momento. Las otras tres son: Nirihuau (mapa 1), Cañadón Asfalto-Somuncurá y Colorado cuenca mixta que se extiende en el continente y el lecho marino.

A fines de 2005, Río Negro puso en marcha el Plan Exploratorio Hidrocarburífero Provincial, un proyecto que buscaba ofrecer tareas de exploración y explotación a empresas petroleras privadas. La iniciativa se enmarcó en una política más general de estímulo a la actividad en sus cuatro etapas básicas (exploración, explotación, transporte y procesamiento), y en un plan integral de energía con base en el aprovechamiento de otros recursos naturales.

Como pasos previos al lanzamiento del plan exploratorio, se llevó adelante la organización de un banco de datos con información técnica y geológica de la región que serviría para generar interés entre los inversores privados - para el cual se utilizaron registros de trabajos de cateo y exploración de la vieja YPF estatal, y de otras firmas petroleras que actuaron en la región-, y se 


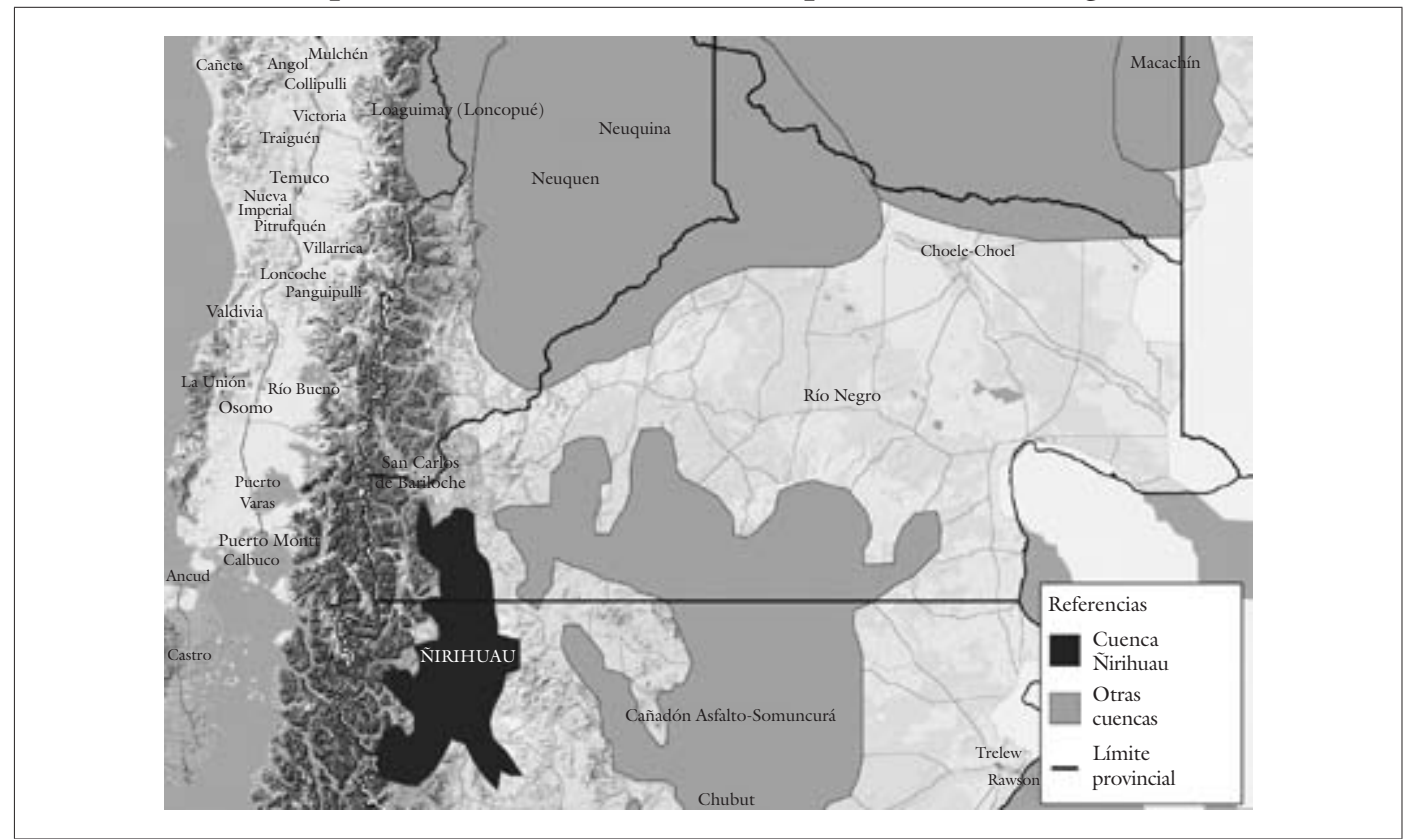

Fuente: Elaboración propia en base al Sistema de Información Geográfica de la Secretaría de Energía de la Nación.

dio impulso a la estatal Edhipsa (Empresa de Desarrollo Hidrocarburífero Provincial Sociedad Anónima), con el objetivo de avanzar en la adjudicación de concesiones mixtas con inversión pública y privada, que permitieran una mayor captación de la renta por parte del Estado.

En mayo de 2006, el plan fue presentado en Houston, Estados Unidos, por el gobernador rionegrino Miguel Saiz. Al mes siguiente se oficializó el cronograma de licitaciones. Las primeras tres rondas culminaron con la adjudicación, entre julio de 2006 y diciembre de 2007, de trece nuevas áreas de exploración y explotación hidrocarburífera — todas pertenecientes a la cuenca neuquina-, totalizando compromisos de inversión por más de Us $\$ 250$ millones. La política de promoción implicó la consolidación de firmas que ya contaban con presencia en la zona, así como el ingreso de otras de capitales medianos y pequeños (Observatorio Petrolero Sur, 2009).

La cuarta y última ronda licitatoria se abrió con un concurso público nacional e internacional en noviembre de 2007. En esta oportunidad, la Dirección General de Hidrocarburos decidió implementar un nuevo sistema de incentivos para la recuperación de inversiones en áreas petroleras que se consideraron de alto riesgo, y que quedaron como remanentes de los proce- territarias 30 
sos licitatorios anteriores. Así, las empresas que lograran adjudicarse la exploración y eventual explotación de los bloques Aguada de Córdoba, El Cuy y Meseta Baya no pagarían regalías hasta que no recuperasen la inversión exploratoria.

Pero sin lugar a dudas, el dato más relevante de esta cuarta ronda licitatoria fue que se optó por avanzar sobre dos áreas pertenecientes a cuencas improductivas hasta el momento: General Conesa - cuenca del Colorado- - y Nirihuau. Esta última se extiende de norte a sur desde el lago Nahuel Huapi hasta Esquel, en Chubut; y de este a oeste comprende desde la localidad rionegrina Río Chico y la chubutense Gualjaina, en el límite oriental, hasta los $71^{\circ} 30^{\prime}$ de longitud oeste.

Como en otras regiones del país, la existencia de manaderos de crudo en $\mathrm{Ni}^{-}$ rihuau era conocida desde la colonia y sus primeros usos como brea para la reparación de embarcaciones o como aceite para iluminación se remontan a aquella época. Luego del descubrimiento de petróleo en Comodoro Rivadavia en 1907, y como respuesta al avance de trusts ingleses y estadounidenses, el Estado nacional - a través de la Dirección de Minas y Geología y luego mediante YPF- redobló los esfuerzos exploratorios en la Patagonia. Así, en Nirihuau se realizaron cateos en 1911 y 1918 ; entre esos años, también hubo intentos de explotación privados, que no resultaron económicamente viables. Entre 1933 y 1934, yPF retomó los trabajos en la zona con un considerable despliegue de personal territarias 30 152 pozos, que hallaron impregnaciones de petróleo en el subsuelo, pero que no lograron encontrar la beta madre ni acceder al mayor reservorio. Al no producirse los descubrimientos esperados, YPF postergó indefinidamente sus actividades en la cuenca (Salas 2007; Arrigoni 2007; Nasser 2011). Como veremos más adelante, el mal sellado de estas perforaciones dejó una huella indeleble en el paisaje, $y$ fue motivo de conflicto con los pobladores del paraje.

Durante la década de 1940, la empresa La Celina se hizo cargo de las exploraciones, y entre 1982-1984 también realizaron estudios Pluspetrol y Esso Argentina, intentando esta última con tres pozos más. Finalmente, en febrero de 1999 la empresa de capitales británicos Emerald Energy (Argentina) Limited recibió un permiso de exploración sobre el área CÑ-01 Ñirihuau, que comprendió $9606 \mathrm{~km}^{2}$ de la cuenca, distribuidos entre las provincias de Río Negro y Chubut. A pesar de las bajas inversiones comprometidas en el contrato - la realización de un pozo exploratorio en seis años-, Emerald Energy fue intimada en febrero de 2004 por el Ministerio de Planificación Federal, Inversión Pública y Servicios de la Nación por incumplimiento de las unidades de trabajo pactadas, al pago de $\$ 825000$, más una actualización por inflación. Al no llegar a un acuerdo respecto del cálculo de los intereses, se canceló el permiso de exploración, y el dominio del área fue revertido a las provincias de Río Negro y Chubut.

Así, hasta el proceso de licitación y adjudicación que analizamos aquí, los esca- 
sos antecedentes de Nirihuau sumaban un puñado de pozos perforados en 90 años.

\section{Reacciones y resistencias}

El bloque que se proponía a licitación tenía una superficie aproximada de 5421,41 $\mathrm{km}^{2}$. Se ubicaba entre los departamentos rionegrinos de Pilcaniyeu y Norquinco, y su límite noroeste se encontraba a pocos kilómetros de la frontera sudeste del Parque Nacional Nahuel Huapi (mapa 2). Este posee un alto valor ecológico y paisajístico, protegiendo una extensa área representativa de la región andina del norte de la Patagonia. Resguarda muestras de tres unidades naturales: altoandino, bos- que andino-patagónico y estepa patagónica (Administración de Parques Nacionales).

Por otro lado, además de lindar con el PN Nahuel Huapi, el área a licitar se ubicaba dentro de la reserva de biosfera Andino Norpatagónica, inscrita en septiembre de 2007 como parte integrante de la Red Mundial de Reservas de la Biosfera auspiciada por la Unesco. ${ }^{1}$

Ninguna de estas áreas protegidas limitó el avance de la concesión extractiva. Numerosas organizaciones sociales, culturales y políticas señalaron los peligros que la puesta en producción acarrearía para la región. Estas advertencias reconocían orígenes diversos según la fuente. Desde consideraciones éticas y sociales inscritas en

Mapa 2. Áreas Ñirihuau (Río Negro) y Ñirihuau Sur (Chubut)

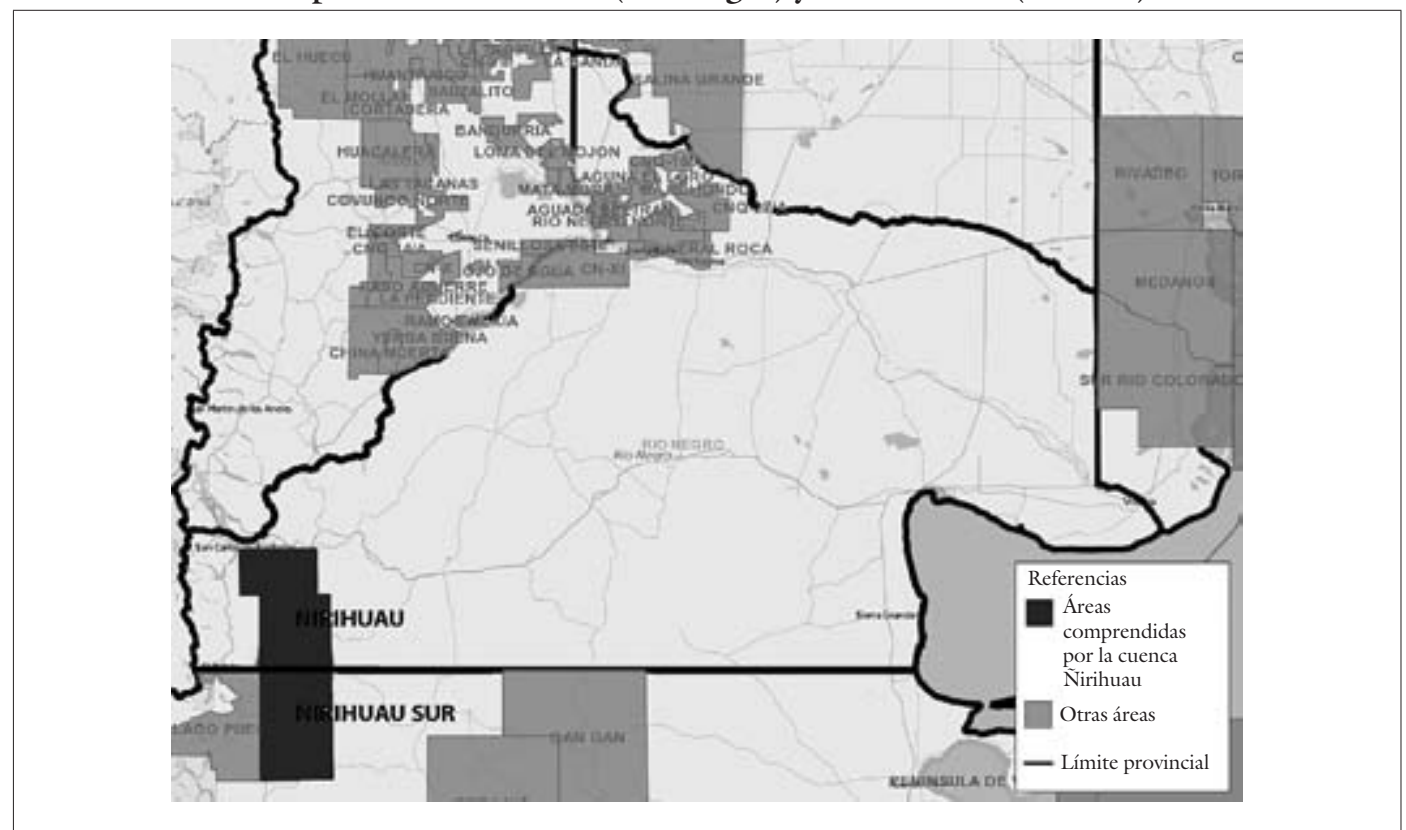

Fuente: Elaboración propia en base al Sistema de Información Geográfica de la Secretaría de Energía de la Nación.

ÑIRIHUAU: EXPLOTACIÓN DE HIDROCARBUROS Y CONFLICTO SOCIAL EN LAS INMEDIACIONES DE BARILOCHE
${ }^{1}$ Elárea Nirihuause encontraba entre zonas de amortiguación y transición. En estas no se probibe explicitamente la extracción de bidrocarburos, pero tienen un rol clave en la conservación de la biodiversidad, y sirven como muestra de procesos de desarrollo sustentables o de bajo impacto. Se trata de "áreas con alta integridad ambiental, que, al igual que las zonas núcleo, contienen especies y sistemas ecológicos de valor especial o representativos, conservan cabeceras de cuenca, bosques protectoresy, conjuntamente con las áreas núcleo a las que rodean, constituyen una superficie de tamaño y estado de conservación adecuado para permitir la permanencia de poblaciones viables de la mayor parte de lasespecies" (Iniciativa Reserva Biósfera Andino Norpatagónica, 2007, p. 22).

territarias 30

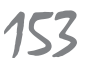


2 Existe una amplia bibliografía relativa a este tipo de conflictos sociales. Enumeramos aqui los que principalmente nos sirvieron de referencia: Giarracca, 2001; Gordillo, 2010; Lenguita y Galafassi, 2004; Moyano, 2007; Piqueras, 2002; Seoane, 2003; Roze y Pratesi, 2005; Galafassi, 2006; Radovich, 2002; Tarrow, 1997; Touraine, 1999; Valverde, 2004.

\section{territarias 30} 154 cosmovisiones alternativas de la sociedad, la naturaleza y el territorio; hasta otras esgrimidas por los sectores sociales que, de prosperar el proyecto, verían afectados sus intereses económicos, y que se expresaron en leves formas de denuncia y protesta (fundamentalmente agentes turísticos y organizaciones diversas vinculadas a esta actividad). ${ }^{2}$

El 19 de febrero de 2008 dos concejales barilochenses del partido Frente Grande presentaron un amparo ante la justicia para frenar el proyecto. Los legisladores argumentaban que la cuenca no se podía licitar ni adjudicar sin realizarse, previamente a la convocatoria, un estudio de impacto ambiental y reclamaban al gobernador que se negara a adjudicar el área hidrocarburífera ante el rechazo popular por los temores generados respecto al posible impacto ambiental en la región. A fines de marzo, en fallo dividido, la Cámara de Apelaciones en lo Civil y Comercial de Bariloche se declaró incompetente para considerar el pedido de prohibición, por lo que el recurso pasó a competencia del Superior Tribunal de Justicia de Río Negro.

Mientras tanto, a pesar de las limitaciones muy precisas y estrictas que la categoría jurídica Parque nacional (PN) imponía a las actividades económicas dentro y en los alrededores de sus fronteras, el entonces intendente del parque nacional Nahuel Huapi, Juan Salguero, se mostraba 'conforme' ante los detalles dados por el gobierno provincial. En respuesta a las primeras críticas al proyecto, manifestó que, a pesar de que el área ofertada se encontraba a 25 kilómetros del Parque, y estaba atravesada por cursos de agua que desembocan en el lago Nahuel Huapi, “están las previsiones ambientales que nos dejan tranquilos, no siendo el único caso de un parque nacional que convive con la extracción de hidrocarburos [...] en el parque nacional Calilegua, en Jujuy, existía un pozo dentro del parque, previo a su creación y también el parque nacional San Guillermo, en San Juan, linda actualmente con un campo petrolero" (Parques en alerta por la exploración petrolera, 2008).

La justificación de Salguero obviaba el hecho de que la explotación del yacimiento Caimancito en el PN Calilegua es ilegal y ha sido objeto de numerosas denuncias de contaminación por parte de los trabajadores del Parque (Observatorio Petrolero Sur, 2012). Con posterioridad y como parte de una estrategia del oficialismo para descomprimir el clima de protesta y movilización, la Administración de Parques Nacionales solicitó la desafectación del área comprendida por la cuenca hídrica del Ñirihuau, al menos en lo relacionado a las aguas superficiales. Sin embargo, de acuerdo al titular de la Región Andina del Departamento Provincial de Aguas, en ningún momento se efectuó un estudio hidrológico exhaustivo que permitiera evaluar el comportamiento de las aguas subterráneas del área licitada (Observatorio Petrolero Sur, 2009).

Con el mismo objetivo se manifestó, en un principio, el Consejo de Ecología y Medio Ambiente de Río Negro (Codema): "Si bien todavía no existe una evaluación de impacto ambiental del emprendimiento licitado en fecha reciente, el Codema 
aseguró que a la hora de elaborarla 'será tenida en cuenta' la cercanía del área protegida”. Además, según dicho organismo, "el área licitada no toca el parque y en caso de iniciarse la explotación los trabajos deberán regirse por las normas ISO 14.001 de certificaciones ambientales" (Parques en alerta por la exploración petrolera, 2008). ${ }^{3}$

Los pobladores del paraje, que viven mayoritariamente en forma precaria de la escasa producción agropecuaria y en parte de actividades colaterales del turismo regional, se opusieron desde un comienzo a la adjudicación dado que el riesgo de afectación del ambiente ponía en peligro su principal fuente de ingresos. De hecho, varias familias ya venían sosteniendo un histórico reclamo con respecto a la contaminación generada por las perforaciones realizadas por YPF en los treinta. El mal sellado de estos pozos generaba emanaciones de petróleo que desembocaban en el arroyo Las Minas, y de allí seguían al Nirihuau y al Nahuel Huapi. La persistencia de este problema durante décadas funcionó como un elemento más de oposición al proyecto, ya que, según se argumentaba, presagiaba en pequeña escala los perjuicios que generaría en la zona una explotación más intensiva de los recursos (Parques en alerta por la exploración petrolera, 2008).

A ellos se sumaron - a medida que se conocían las condiciones de adjudicación y las características del bloque Nirihuauotros pobladores urbanos agrupados en organizaciones ambientalistas como la Comunidad del Limay, centros de estudiantes de escuelas medias de la zona, el sindicato docente de la provincia y ciudadanos autoconvocados. Muchos de ellos estaban vinculados al turismo, que como actividad económica fundamental en la zona, se nutre del ambiente como insumo y necesita, por lo tanto, ciertas condiciones ambientales mínimas.

Las acciones tomadas por estos grupos reafirmaron su rechazo a la explotación petrolera que, presumiblemente, alteraría su forma de vida y contaminaría el medio ambiente. La estrategia seguida en reclamo de respuestas por parte de las autoridades tuvo como principal interpelado al mencionado Codema. Sin embargo, los reiterados pedidos de garantías ambientales - particularmente, la realización de una audiencia pública y de un estudio de impacto ambiental-, encontraron el silencio y la negativa de las autoridades provinciales.

"El 26 de marzo [de 2008] los habitantes del Valle del Nirihuau junto a vecinos de Bariloche y la organización ambientalista Comunidad del Limay esperaron en vano al titular de la dependencia [Codema], Oscar Echeverría, que se había comprometido a participar de una reunión en la escuela de Ñrihuau Arriba" (Gavaldà y Scandizzo, 2008, s. n.). El funcionario fue intimado a través de una carta documento a presentarse en la escuela del paraje para brindar las explicaciones requeridas por los ciudadanos y organizaciones. Cuando finalmente lo hizo, el 26 de abril, fue para deslindar responsabilidades e involucrar en este sentido a la Subsecretaría de Minería e Hidrocarburos provincial.
${ }^{3}$ Al respecto, debemos remarcar que en numerosos casos vinculados a la industria hidrocarburifera en Argentina, las normas de certificación ISO no fueron salvaguarda para evitar la afectación del sistema ecológico (ver Piotto, 2002; Fernández, 2003; Gavaldà y Scandizzo, 2010).

territarias 30

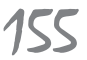


Días antes, la situación había llegado a manos de la Defensoría del Pueblo de la provincia de Río Negro. Ante la falta de respuestas y por sentirse "ajenos a decisiones que impactan directamente en el lugar" (Argentina, 2008), las organizaciones y autoconvocados solicitaron la directa intervención de la Defensora, quien se hizo eco de las preocupaciones, e instó a la realización de una audiencia pública "como mecanismo de participación ciudadana en la toma de decisiones por parte del Estado" (Argentina, 2008). Asimismo, recomendó a los municipios potencialmente afectados (San Carlos de Bariloche, Pilcaniyeu y Norquinco) y a sus concejos deliberantes, que tomaran directa intervención en la problemática, dado que, al tratarse de una actividad que influiría en el ecosistema local, correspondía una participación activa en defensa de sus intereses.

Entretanto, con el propósito de 'tranquilizar' a los sectores movilizados, la Subsecretaría de Minería e Hidrocarburos brindó detalles de las características de la explotación. En declaraciones a la prensa, sostuvo que "las exigencias en materia medioambiental estipuladas por el pliego de bases y condiciones habían sido especialmente determinadas en función del área objeto de la licitación, reparando en una fuerte exigencia normativa en el cuidado del medio ambiente". Asimismo, y como si se tratara de un aliciente con respecto a las posibilidades de contaminación, detalló que "el interés del Ñirihuau es gas, no petróleo" (Parques en alerta por la exploración petrolera, 2008). Esta argumentación del oficialismo pasaba por alto que la explotación gasífera tampoco es inocua, ya que de todas maneras implica trazado de caminos, prospecciones, pozos exploratorios y afectación del territorio por la instalación de cientos de kilómetros de gasoducto.

Desde su cosmovisión alternativa, el pueblo mapuche manifestó una oposición más radical al proyecto. Las razones de este cariz se deben rastrear en el proceso de lucha por la 'recuperación ancestral' de tierras en el valle del río Nirihuau, iniciado por la comunidad Lof Inkaial Wal Mapu Meu en medio de este conflicto. A diferencia de la estrategia adoptada por los pobladores autoconvocados y las organizaciones ambientalistas, sindicales y estudiantiles - que buscó seguir los mecanismos institucionales-, los comuneros indígenas combinaron la acción directa con apelaciones al derecho formal que resguarda sus intereses en materia económica, política, social y cultural.

El 11 de octubre de 2008, un grupo de mapuches residentes hasta ese momento en los barrios periféricos de la ciudad de Bariloche, iniciaron dicha 'recuperación ancestral', instalándose en un predio a orillas del río Nirihuau y la confluencia con el arroyo Tristeza, en un área ubicada dentro de los límites del parque nacional Nahuel Huapi en su frontera sudeste. La misma se basó en principios que, más que con la historia inmediata y con los antecedentes cercanos vinculados a la ocupación de esa área en particular, tenían que ver con derechos históricos de más largo plazo, directamente relacionados con el despojo inicial del cual fueron víctimas las poblaciones de 
indígenas de la Patagonia (Walther, 1976; Curruhuinca y Roux, 1984; Mases, 2002). Asumían así como un proceso inconcluso la lucha llevada adelante por las comunidades mapuches en el siglo XIX, cuando intentaron frenar el avance de las tropas y el proceso colonizador avalado por la legalidad inherente a la Constitución argentina.

El carácter de 'recuperación ancestral' dado a este proceso tuvo un elemento de fundamental particularidad, por cuanto en este caso no se remitían a una presencia inmediata en el territorio, ya fuera esgrimiendo que ellos mismos venían siendo ocupantes de hecho de la tierra, o bien que por generaciones, aunque sin títulos, esa tierra fue ocupada por población mapuche. El solo hecho de constituir una porción de territorio por donde históricamente (es decir, en el largo plazo de siglos) hubiera habido alguna presencia indígena fue suficiente para argumentar el derecho al regreso al territorio.

Este derecho al regreso era esgrimido como sostén principal del proceso de recuperación. En el mismo subyacía una clara diferenciación entre los conceptos de tierra y territorio. El primero tiene un claro arraigo en la sociedad de mercado y remite a un simple factor de producción. Desde el significado mapuche, el concepto de territorio, en cambio, hace referencia a un componente esencial en su estructura de vida en tanto pueblo, en tanto unidad entre cultura, producción y vida cotidiana. El mismo "permite ir más allá del elemento material, actúa como espacio generador y reproductor de la identidad del grupo, y por lo tanto, como cohesionador de la organización" (Valverde, 2004, p. 59).

Es tan importante la integración a un territorio, que la ausencia del mismo es sinónimo de alienación y de destrucción no solo de la identidad como pueblo, sino incluso de los valores básicos por ellos considerados como pilares de la 'gente de la tierra'. Por lo tanto, el hecho de que el proyecto de exploración y explotación de hidrocarburos en Nirihuau implicara una ruptura con la noción integral de territorio y la cosmovisión de que 'somos parte de la tierra', los llevó a adoptar posiciones más críticas y radicales que las que venían mostrando los otros sectores sociales y políticos también opuestos a la iniciativa.

Si bien la gente piensa que una audiencia pública que no es vinculante puede llegar a ser una solución, nosotros decimos que no [...] nosotros tenemos que pararlo de la manera que sea $[. .$.$] la cuestión ecologista va por un$ lado y la mapuche por otro lado. La cuestión mapuche se entiende de otra manera, ¿̨cómo van a dañar el territorio, cómo vamos a permitir que realicen una actividad petrolera que va a contaminar? [...] Eso significa la muerte de un montón de seres vivos y fuerzas que esta tierra tiene. Nuestro análisis no es cuánto va a contaminar, queremos que se vayan, no queremos petroleras en el territorio, no queremos eso para el futuro de nuestros hijos" (Bariloche2000, 2008).

Como decíamos, las reivindicaciones anteriores se combinaron con apelaciones al derecho formal. En este caso, de todos territarias 30

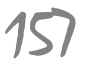


los instrumentos legales que resguardan los intereses de los pueblos originarios, el más citado fue el Convenio 169 de la OIT —ratificado por Argentina mediante la Ley 24071 de 1992 - , que establece el derecho de consulta libre, previa e informada de los pueblos indígenas ante cualquier proyecto que afecte su territorio. El Consejo Asesor Indígena (CAI), a través de su coordinación, manifestó sobre la inobservancia de dicho convenio:

Si [el gobierno] no informa al conjunto de la sociedad menos van a informar a los pueblos originarios, con el pensamiento y la actitud racista que tienen. No lo hicieron, no esperamos que lo hagan tampoco. Es bien evidente la negación de nuestra existencia por el gobierno de Río Negro, continuamente está tratando de comerciar el territorio. En su momento puso en discusión al mercado internacional la minería, las tierras - las 5 millones de hectáreas que ellos dicen que son fiscales [y el CAI reivindica territorio mapuche]_, también el caso de la forestación para que se produzca pino en gran escala. Hace poco tiempo la soja y ahora el petróleo (Gavaldà y Scandizzo, 2008, s. n.).

Finalmente, el amparo presentado por los legisladores del Frente Grande de Bariloche logró demorar el proceso licitatorio, pero fue en última instancia rechazado por la justicia ordinaria en septiembre. Al mes siguiente, el área resultó adjudicada a la Unidad Transitoria de Empresas (UTE) YPF S. A. - Pluspetrol S. A., por medio del Decreto 1071-que fue publicado en el Bole- tín Oficial de la provincia el 3 de noviembre de aquel año, prácticamente un mes después de su firma. El decreto reconocía un “permiso de exploración y eventual explotación, transporte y comercialización de hidrocarburos en la provincia de Río Negro", y establecía que la contratista debía llevar adelante sus tareas en una primera etapa de exploración, en la que se debían cumplir de manera irrevocable las unidades de trabajo comprometidas mayormente en muestreos geoquímicos de superficie - equivalentes a una inversión de US\$17763050, muy superiores a las pactadas con Emerald Energy en 1999- y una segunda de explotación y desarrollo, en caso de realizar descubrimientos de hidrocarburos.

La adjudicación motivó una nueva intervención de la Defensoría, que mediante la resolución 139/08 volvió a recomendar a los municipios involucrados la realización de una audiencia pública (con el debido concurso del Poder Ejecutivo provincial y los órganos competentes); solicitó la suspensión del Decreto 1071; e instó a diversas autoridades nacionales (defensor del Pueblo de la Nación, Consejo Federal de Medio Ambiente, director de Parques Nacionales) a tomar parte en el conflicto. Sin embargo, el carácter no vinculante de la resolución, la privó de incidencia efectiva en el curso de los acontecimientos. De esta manera, pese a las críticas, la adjudicación se mantuvo en pie.

Por su parte, las relativas coincidencias entre los vecinos del paraje y los integrantes de la comunidad mapuche Lof Inkaial WalMapu Meu se limitaron a la oposición al 
proceso licitatorio de la cuenca hidrocarburífera. Estos vecinos - pobladores históricos reconocidos por las autoridades del Parque- se opusieron firmemente al proceso de recuperación, a pesar de la intención de la comunidad mapuche de respetar el área de pastoreo tradicional. Según lo poco que se ha podido saber a través del trabajo de campo y las entrevistas, la escalada del conflicto fue subiendo en intensidad llegando a momentos de importante rispidez. El hermetismo de los diferentes actores impidió conocer mayores detalles, pero lo cierto es que finalmente la comunidad que generó el proceso de recuperación ancestral y los pobladores históricos del área decidieron poner fin al conflicto acordando entre ellos, a mediados de noviembre del año 2008, los pasos a seguir. Esto implicó el retiro del grupo mapuche que realizó originalmente el proceso de recuperación ancestral, quedando supuestamente la defensa del territorio en manos de los pobladores históricos (Galafassi, 2012).

Este hecho fue sintomático de una tensión que nunca se llegó a resolver y que en parte respondía a diferentes cosmovisiones acerca del territorio. De un lado, aquellas que lo consideraban como mero soporte de actividades productivas o económicas en un sentido más amplio - como el turismo-; del otro, las que, desde una lectura histórica de largo plazo, lo reivindicaban como base objetiva para la reproducción de vínculos comunitarios, prácticas culturales y para la proyección de sentido e identidad. Estas diferencias sin dudas influyeron en la determinación de las diferentes estrategias

ÑIRIHUAU: EXPLOTACIÓN DE HIDROCARBUROS Y CONFLICTO SOCIAL EN LAS INMEDIACIONES DE BARILOCHE a seguir, y provocaron un desencuentro que, en términos generales, debilitó al movimiento de oposición al proyecto. Así, si bien existió una comunidad de intereses entre ambas posturas, esta no se tradujo en una articulación mediante la cual se coordinaran acciones de lucha y protesta.

\section{La expansión de la frontera hidrocarburífera argentina y el futuro de Nirihuau}

La adjudicación del área significó un revés para los diversos sectores que se oponían al proyecto. Sumada a las desavenencias recién descritas, provocó una merma en el estado de movilización previo, a partir de la cual la licitación pareció imponerse como hecho consumado. Sin embargo, es de destacar que en los meses subsiguientes las empresas no realizaron avances sustanciales en las tareas de cateo y exploración. Por lo tanto, a partir de aquí se puede observar que las demandas que cobraron mayor incidencia en la agenda pública fueron las relacionadas con la necesidad de contención y remediación de los manaderos ocasionados por las perforaciones de las décadas anteriores, siendo los pobladores de la zona los principales protagonistas en esta nueva etapa del conflicto.

En los meses previos al Decreto 1071, la provincia se había comprometido a realizar las tareas necesarias a través del Departamento Provincial de Aguas, como requisito previo a la celebración del contrato con la UTE YPF-Pluspetrol. De esta manera, se instalaron tuberías y tanques para trasladar

territarias 30

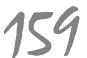


4 Como señaló la legisladora Meana Garcia - quien presentó el proyecto en el recinto - la ley debía subsanar la falta de una "norma que establezca planes y conductas claras para la situación en que el daño haya sido producido. Esto normalmente se contempla en los contratos petroleros, se incluyen cláusulas, pero es importante que así como a nivel provincial y a nivel nacional tenemos leyes de protección ambiental $y$ de prevención que establecen contenidos minimos y que songenerales - no referidas al caso concreto- se apruebe y se sancione una ley como esta que establece contenidos minimos de reparación del daño ambiental" (Argentina, 2011, p. 160).

\section{territarias 30} 160 y contener los hidrocarburos que emanaban de los viejos pozos. Sin embargo, la utilización de materiales inadecuados y la falta de mantenimiento, no hicieron más que empeorar la situación. En octubre de 2009, se sucedieron nuevas protestas por parte de los vecinos y un pedido de informes presentado en la legislatura provincial por integrantes del partido SUR (Solidaridad y Unidad por Río Negro), en el que se solicitaban detalles de los trabajos realizados y el plan de remediación (Agencia Digital de Noticias, 2009; No cesan los derrames de petróleo, 2009).

En marzo de 2010, el Codema respondió a dicha solicitud, asegurando que las tareas de saneamiento del arroyo Las Minas habían sido efectivas y garantizando las restantes tareas de remediación (El Codema garantiza la remediación del Nirihuau, 2010). Finalmente, estas quedaron comprendidas dentro de un plan de remediación ambiental aprobado por la legislatura provincial en junio de 2011 , que buscaba "cuantificar los daños y pasivos causados por la explotación y exploración de hidrocarburos al medio ambiente, a la salud de la población y a los fundos superficiales" y establecía una serie de objetivos relacionados con las tareas de reparación (Argentina, 2011). ${ }^{4}$

Simultáneamente, Nirihuau volvió a figurar entre las noticias del negocio petrolero. En diciembre de 2010, la provincia de Chubut anunció la convocatoria a licitación de cinco nuevas áreas, entre las que se encontraba Nirihuau Sur. En marzo de 2011, el bloque recibió ofertas de una UTE con- formada por las empresas Andes Energía Argentina y Kilwer, esta última presidida por el ex ministro del Interior del menemismo, José Luis Manzano (Subsecretaría de Medios y Comunicación Pública de Chubut, 2011). En junio de 2011 el bloque CN-01 Nirihuau Sur fue adjudicado a un joint venture en el que Andes Energía y Kilwer participan con un $60 \%$ y un $20 \%$, respectivamente, y al cual se integró la estatal provincial Petrominera Chubut, con el $20 \%$ restante de participación en las ganancias. La licencia de exploración fue otorgada por seis años, y en los primeros tres se recolectarán 3000 muestras geoquímicas, y se generarán y reprocesarán 200 km de sísmica 2D.

Por otro lado, en abril de 2012, en el marco del conflicto que enfrentó a la compañía transnacional Repsol y al gobierno argentino, Río Negro decidió la anulación de la concesión del área hidrocarburífera Ñirihuau. Así lo explicó el gobernador Alberto Weretilneck:

[la decisión] se toma en virtud de la falta de cumplimiento de la empresa a los compromisos de inversión estipulados en los respectivos contratos $[\ldots]$ YPF se había comprometido en el contrato firmado a realizar inversiones y no lo hizo, y por otro lado estamos absolutamente convencidos que en todo el departamento de San Carlos de Bariloche no pueden haber exploraciones de petróleo ni de minería que afecten el medio ambiente [...] Lo que habíamos anunciado con la palabra, ahora lo estamos confirmando con los hechos: Bariloche está fuera de cualquier tipo

Guido Galafassi, Diego Pérez Roig 
de explotación que tenga que ver con riesgos para el medio ambiente, por más rentable que fuere" (No habrá minería ni extracción de petróleo en la zona de Bariloche, 2012).

A pesar del reflujo posterior a noviembre de 2008, consideramos que en este desenlace no se debe subestimar la importancia de todo el proceso de movilización. Como atestiguan las declaraciones del gobernador, aquel rechazo al proyecto se mantuvo latente, y el argumento ambiental fue un elemento importante - no solo en este caso- ${ }^{5}$ en torno al cual generar consensos para la anulación de la concesión.

No obstante, la licitación y adjudicación de Nirihuau Sur en la provincia de Chubut, marca la pauta de que estos conflictos en la región, lejos de encontrar una resolución definitiva, tenderán a agudizarse. En la actualidad, el avance territorial de la industria hidrocarburífera argentina ha logrado contornos bien definidos. De las diez provincias que participan de la actividad, solo seis pueden —basadas en volúmenes de extracción y antecedentesreclamar para sí el título de 'petroleras': Salta, Mendoza, Neuquén, Chubut, Santa Cruz y Tierra del Fuego. No obstante, si ampliamos el espectro de nuestra mirada contemplando el hecho de que la industria petrolífera y gasífera demanda años de estudios e inversiones previas a la etapa estrictamente extractiva, nos encontraremos con que la totalidad del territorio argentino - excluyendo a la Capital Federal-, está involucrado de una u otra forma con la actividad. Las provincias que aún no cuentan con explotaciones efectivas, sí han iniciado su camino a partir de consultorías técnicas, reformas de marcos regulatorios, creación de empresas locales de energía, rondas licitatorias, y trabajos de cateo y exploración. Este proceso, cuya génesis se puede ubicar entre los años 2003-2006, ha recibido un nuevo impulso a partir de la recuperación del control de YPF por parte del Estado nacional, y el lanzamiento del plan quinquenal 2013-2017 que prevé la perforación de 250 nuevos pozos exploratorios (YPF, 2012).

En este fenómeno expansivo, que por su velocidad y extensión se asemeja al despliegue territorial de otras actividades extractivas - como la minería a cielo abierto--, confluyen una serie de factores.

En primer término, la matriz energética argentina, altamente dependiente del consumo de hidrocarburos, sobre todo de gas. El $35 \%$ de la oferta interna de energía primaria se obtiene a partir de petróleo, y un $51,6 \%$ a partir de gas natural (Secretaría de Energía de la Nación, s. f.).

Por su parte, la imposición del neoliberalismo, y su persistencia como patrón de acumulación durante el período 19762001, legó una serie de consecuencias ineludibles para la comprensión de la situación actual del sector hidrocarburífero, sus reconfiguraciones técnicas y su expansión territorial en ciernes. El primero de los elementos tiene que ver con la situación fiscal de las provincias, castigada a dos bandas por la destrucción de las economías regionales y el proceso popularmente conocido como de 'desguace del Estado'. No resulta
$5 n$ esos primeros meses del año, Repsol-rPF perdió concesiones de áreas en extracción en Chubut, Santa Cruz, Neuquén, Mendoza, Salta y Río Negro. En ese momento, y también en la posterior publicación del Informe Mosconi, se insistió en la deficiente gestión ambiental de la empresa como causal de revocatoria. territarios 30

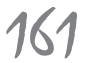


extraño que, a pesar de las magras regalías, muchas provincias perciban en la radicación de la industria hidrocarburífera en sus territorios la posibilidad de aumentar el 'financiamiento interno' — captando parte de la renta generada por dicha actividad-, para, consecuentemente, incrementar sus niveles de autonomía política y económica con respecto al gobierno federal.

La imposición del neoliberalismo también se cristalizó en las medidas desregulatorias y privatizadoras implementadas fundamentalmente en la década de 1990, que negaron el carácter estratégico de los hidrocarburos y los convirtieron en simples commodities. Estas reformas estructurales habilitaron y estimularon la política predatoria de las empresas privadas, que orientadas por una inmediata valorización de las concesiones, priorizaron la sobreexplotación de los pozos ya productivos - $\mathrm{O}$ en las áreas cuyo potencial había sido verificado por las inversiones de riesgo hechas por la YPF estatal durante décadas-, y la exportación de lo extraído, en desmedro de la reposición de reservas y el futuro abastecimiento del mercado interno. Argentina alcanzó su pico de producción de petróleo en 1998 y el de gas natural en 2004. Desde entonces, la extracción de hidrocarburos de yacimientos tradicionales viene decreciendo año a año (Secretaría de Energía de la Nación s. f.).

Esta merma fue acompañada por una fuerte recuperación macroeconómica iniciada en 2002-2003, que llevó el PIB de Us\$102 mil millones a Us\$446 mil millones en 2011 (Banco Mundial). Como es lógico, también se incrementó el consumo de energía, sobre todo a partir de la explotación de hidrocarburos, habida cuenta de las peculiaridades de la matriz energética nacional. El escenario de disminución de la extracción y retraimiento de las reservas, sumado al crecimiento en la demanda de los últimos años, ha redundado en ingentes importaciones de combustibles, que se han convertido en uno de los principales desequilibrios de la balanza comercial. De 2003 a 2010, estas se incrementaron un $715 \%$, pasando de Us $\$ 549$ millones, a us $\$ 4474$ millones. En 2011 y 2012 se produjo un nuevo salto, llegando a US $\$ 9400$ y us $\$ 9500$ millones, respectivamente ( $\mathrm{Mi}$ nisterio de Economía de la Nación, s. f.).

Este fue el factor que terminó de desencadenar el conflicto entre el gobierno nacional y Repsol a comienzos de 2012. Si bien la recuperación estatal del control de YPF y el nuevo marco regulatorio constituyen una clara ruptura con diversos preceptos del modo de gestión neoliberal, la búsqueda de una solución a la caída de la producción y las reservas a partir de la exploración y explotación de yacimientos no convencionales - tal como figura en el nuevo plan quinquenal de la compañía-, con miras a una posible generación de saldos exportables, tensionará aún más los movedizos contornos geográficos de la actividad (ver Pérez et ál., 2012), abriendo nuevos frentes de conflictos socio-ambientales.

En efecto, la posibilidad de extraer hidrocarburos en regiones otrora 'marginales' como Nirihuau, ha recibido un nuevo impulso en los últimos años a partir del 
desarrollo de la técnica, particularmente las tecnologías de perforación horizontal y fractura hidráulica (fracking en inglés) que se utilizan para explotar reservorios de shale gas, shale oil y tight gas. El marco internacional dado por un irreversible agotamiento de fuentes tradicionales de hidrocarburos, la creciente demanda de las principales potencias económicas y un aumento de sus cotizaciones internacionales, ha facilitado la puesta en valor de áreas antes consideradas secundarias por su inviabilidad, tanto desde el punto de vista técnico como el económico. Se trata de regiones con escasos o nulos antecedentes en la materia, que albergan entramados productivos, formas alternativas de producción y consumo, y recursos naturales, que no se podrán compatibilizar con el desarrollo de la industria hidrocarburífera.

\section{Consideraciones finales}

Toda América Latina, desde su conquista y colonización por las naciones europeas, fue subdividida en áreas extractivo-productivas según el recurso estratégico presente. Estos territorios complejos fueron mutando y transformándose de acuerdo a la dinámica del capitalismo en desarrollo global y a los vectores geopolíticos presentes en cada coyuntura particular. Si durante la colonización española fue el trabajo esclavo o semiesclavo la fuente principal a partir de la cual se extraían y luego exportaban los recursos, a partir de la constitución de naciones latinoamericanas independientes, fue, y sigue siendo, el comercio desigual bajo condiciones de periferia y dependencia económica y política lo que determina los principios de la extracción-producción-exportación de los recursos. En este proceso, los pueblos originarios en tanto primeros ocupantes del territorio resultaron ser un estorbo por cuanto obstaculizaban el uso de los mismos para todos estos proyectos extractivos. Infinitas son las fuentes que destacan el genocidio, la reducción y la marginación como la política seguida tanto por el coloniaje como luego por los estados-nación independientes.

De la mano del proyecto neoliberal, y siguiendo la tónica dominante en toda América Latina, en Argentina se produjo una reestructuración del capital que, en parte, relanzó su perfil como un gran exportador de materias primas provenientes de la explotación de sus recursos naturales. La Patagonia no escapó a ese destino, sino que, por el contrario, potenció este papel histórico, sumando a la producción intensiva de energía, la mercantilización extrema de las tierras públicas o comunitarias que aún quedaban, tanto para especulación inmobiliaria como para diversos emprendimientos ligados a la producción de commodities o el cercamiento y usufructo privado de paisaje.

Fue en la década de 1990, cuando leyes y decretos varios tuvieron como objetivo facilitar el control privado sobre el gas y el petróleo, creándose, por tanto, un mercado que permitía su libre disponibilidad y libre exportación. YPF se transformó primero en una sociedad anónima con capital abierto, para luego ser definitivamente territarias 30

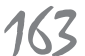


privatizada bajo control de la trasnacional de origen español Repsol. Como señalamos anteriormente, este proceso implicó que el petróleo, de su carácter de recurso estratégico, pasara a asumir un rol de simple commodity regulado en base exclusiva a las fuerzas del mercado. En este marco, si los hidrocarburos en algún momento constituyeron un elemento relativamente promotor de asentamientos poblacionales y de desarrollo, en las últimas dos décadas operaron como productos exclusivamente ligados a la apropiación de renta por muy pocos capitales.

Estos renovados procesos de cercamiento y de acumulación por la vía del despojo de los recursos conllevan un muy alto nivel de destrucción de las condiciones ambientales, comunitarias y regionales. Asimismo, el fuerte carácter de capital transnacional y estacionario de los emprendimientos, hace recaer todas las consecuencias de la contradicción capital-naturaleza sobre los sectores más desfavorecidos por la correlación de fuerzas (pueblos originarios, trabajadores, pequeña burguesía y profesionales), mientras los capitales concentrados se retiran una vez agotado el recurso. Como señalamos, en el caso analizado, estas capas sociales lograron una relativa confluencia que se expresó en el rechazo al proyecto, aunque luego ensayaron estrategias divergentes que debilitaron sus posibilidades de oposición efectiva.

Nos interesa remarcar las acciones del pueblo mapuche, que desde un punto de vista más general, puede caracterizarse como uno de los pueblos originarios que viene encarando con más fuerza la lucha por la recuperación del territorio en el sur de América. Ya son de carácter cotidiano la aparición de conflictos por la tierra tanto del lado chileno como del argentino. En muchos casos estos conflictos han llegado a situaciones de criminalización y represión, por cuanto el cruce de intereses con el capital resulta muchas veces un factor central, estorbando el reclamo mapuche los planes de negocios de importantes agentes económicos.

Las demandas centrales en el caso mapuche pasan fundamentalmente por el reconocimiento de su autonomía, de su independencia de toda estructura política ajena a su identidad (Radovich, 1992). Y esta autonomía tiene al territorio y la cultura como los pilares básicos para poder desarrollarse (Sánchez, 2006); sin estos componentes se hace imposible que puedan ser reconocidos como pueblos. Así, los estados nacional y provincial son vistos como representantes directos de todos los intereses que buscan que el territorio sea solo el soporte de las diferentes estrategias de extracción y explotación de los recursos, a través de la ocupación vía institucionalización de la propiedad privada, que obviamente no los incluye, sino que por el contrario, los expulsa.

En este sentido, la oposición al proyecto de exploración y eventual explotación de hidrocarburos en Nirihuau, se enmarcó en una estrategia más general de recuperación de tierras de las cuales los pueblos originarios se consideran expulsados. La resistencia a no seguir siendo enajenados o invadidos 
por diferentes proyectos de explotación de recursos concentran buena parte de las luchas en estos últimos años. Estas disputas alcanzan, en forma creciente, formatos cada vez más violentos, adquiriendo no solo ribetes judiciales, sino incluso dando lugar a la intervención de diversas fuerzas de seguridad, provinciales o nacionales.

Todo el entramado jurídico-normativo utilizado para avalar estos procesos extractivos, es el mismo que condena todo acto de los pueblos originarios que tenga como fundamento el reclamo por su tierra. Paradójicamente, en muchas oportunidades las comunidades mapuches se han valido de este entramado, amalgamado con derechos ancestrales y humanos en pos de dar sustento a procesos de 'recuperación ancestral'. En nuestro caso, la Comunidad Lof Inkaial Wal Mapu Meu, al desconocer explícitamente la 'conquista del desierto', desconoce en consecuencia el hecho consumado de la violencia armada que fue el origen de la legitimación jurídica que avala, para la 'civilización', la expulsión del territorio y el arrinconamiento en reducciones y espacios marginales.

El proyecto extractivo de Nirihuau los enfrentó nuevamente al despojo originario por cuanto la imposibilidad de disponer de su territorio, se vuelve permiso absoluto para su uso por el capital petrolero. Es el proceso de despojo característico de la llamada 'acumulación originaria' el que vuelve recurrentemente a estar presente aún en el siglo XXI (ver Harvey, 2004; Bonefeld, 2012; De Angelis, 2012). Los cercamientos, en tanto fragmentaciones y apropiaciones privadas del territorio para uso productivo por parte del capital, se diversifican y recrean en estas latitudes, para terminar de abrirlas e integrarlas al mercado mundial de materias primas.

\section{Referencias}

Adjudicaron a YPF-Pluspetrol la exploración de la cuenca Nirihuau (31 de octubre, 2008), ANB. Recuperado de http:// www.anbariloche.com.ar/noticia. php? nota $=5969$

Agencia Digital de Noticias. 2008. Saiz adjudicó exploración de Nirihuau a YPF - Pluspetrol, 3 de agosto de 2008. Recuperado de http://www.barilochense. $\mathrm{com} /$ notas/saiz-adjudico-exploracionde-nirihuau-a-ypf-pluspetrol?expo=1

Agencia Digital de Noticias. 2009. Nirihuau hoy: contención a medias de manaderos de petróleo, 13 de octubre de 2009. Recuperado de http://intra.ada.gba. gov.ar/intra/infoagua/200910/noticias/285327.html

Argentina, Legislatura de la Provincia de Río Negro. Ley 4680, Establece requisitos para la permanencia de las empresas inscriptas en el Registro Provincial de Renegociación de Concesiones de Explotación de Áreas Hidrocarburíferas Rionegrinas creado por la Ley 4571 ( 7 julio 2011).

Argentina, Defensoría del Pueblo de Río Negro. Resolución 139, Resolución de la Defensoría del Pueblo de Río Negro ante la licitación en Nirihuau (5 noviembre 2008). territarias 30

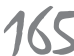

ÑIRIHUAU: EXPLOTACIÓN DE HIDROCARBUROS Y CONFLICTO SOCIAL EN LAS INMEDIACIONES DE BARILOCHE 
Arrigoni, G. (2007). Historias del petróleo. Buenos Aires: Ediciones Atlántico.

Bandieri, S. (2005). Historia de la Patagonia. Buenos Aires: Editorial Sudamericana.

Bariloche2000. (15 de octubre, 2008). Recuperación Mapuche: "Hay que parar como sea" la explotación petrolífera de Nirihuau. Avkin Pivke Mapu. Recuperado de http://www.avkinpivkemapu.com.ar/index.php?option=com content\&task $=$ view\&id $=405 \&$ Itemid $=15$

Bonefeld, W. (julio-diciembre, 2012). La permanencia de la acumulación primitiva: fetichismo de la mercancía y constitución social Theomai, (26). Recuperado de http://www.redalyc.org/ pdf/124/12426097011.pdf

Cueva, A. (1986). El desarrollo del capitalismo en América Latina. México D. F.: Siglo XXI Editores.

Curruhuinca, C. y Roux, L. (1984). Las matanzas del Neuquén. Crónicas mapuches. Buenos Aires: Plus Ultra.

Crean plan de remediación para extracción de crudo (4 de junio, 2011). Rio Negro. Recuperado de http://www. rionegro.com.ar/diario/crean-plande-remediacion-para-extraccion-decrudo-636775-9708-nota.aspx

De Angelis, M. (julio-diciembre, 2012). Marx y la acumulación primitiva: el carácter continuo de los "cercamientos" capitalistas. Theomai, (26). Recuperado de http://www.redalyc.org/articulo. oa?id=12426097003

territarias 30
Negro. Recuperado de http://www. rionegro.com.ar/diario/el-codemagarantiza-la-remediacion-del-nirihuau321476-9708-nota.aspx

Fernández, J. (22 de julio, 2003). El Carrizal: confirman presencia de hidrocarburos en pozos de agua. Los Andes. Recuperado de http://www.losandes.com.ar/notas $/ 2003 / 7 / 22 /$ sociedad-78901 asp

Galafassi, G. (2006). Cuando el árbol no deja ver el bosque. Neofuncionalismo y posmodernidad en los estudios sobre movimientos sociales. Theomai, (14). Recuperado de http://revista-theomai. unq.edu.ar/numero14/ArtGalafassi.pdf

Galafassi, G. (2012). Recuperación ancestral mapuche. Divergencias ideológicas y conflictos entre Mapuches y el Estado. Cuadernos de Antropología Social, (35), 71-98.

Gavaldá, M. y Scandizzo, H. (2010). Patagonia Petrolera, el desierto permanente. Buenos Aires: Observatorio Petrolero Sur.

Gavaldà, M. y Scandizzo, H. (1 de abril, 2008). Nirihuau: nuevo destino petrolero en territorio mapuche. Indymedia Argentina. Recuperado de http:// argentina.indymedia.org/news/2008 /04/591589.php

Giarracca, N. (comp.). (2001). La protesta social en la Argentina. Buenos Aires: Alianza.

Gordillo, M. (2010). Piquetes y cacerolas. El Argentinazo del 2001. Buenos Aires: Sudamericana.

Harvey, D. (2004). El nuevo imperialismo. Madrid: Akal. 
Iniciativa Reserva Biósfera Andino Norpatagónica. (2007). Formulario de propuesta de reservas de biosfera. Recuperado de http://copade.neuquen.gov.ar/intranet/files/FormularioRB_Final_COMPLETO.pdf

Legislatura de Río Negro. (2011). Diario de sesiones, 2 de junio de 2011. Recuperado de http://www.legisrn.gov.ar/DIARIO/D00840.PDF

Lenguita, P. y Galafassi, G. (comps.). (2004). Nuevas prácticas políticas insumisas en Argentina. México-Buenos Aires: Libros en Red.

Mases, E. (2002). Estado y cuestión indígena. El destino final de los indios sometidos en el sur del territorio (1978-1910). Buenos Aries: Prometero Libros-Entrepasados. Ministerio de Economía de la Nación. Información económica al día. Sector externo. Recuperado de http://www.mecon. gov.ar/peconomica/basehome/infoeco.html

Moyano, A. (2007). Crónicas de la resistencia mapuche. Bariloche: El Autor.

Nasser, K. (26 de marzo, 2011). El crudo rionegrino nació en Nirihuau. Río Negro. Recuperado de http://www.rionegro. com.ar/diario/el-crudo-rionegrinonacio-en-nirihuau-587155-10948-notas_energia.aspx

Navarro, P. (1999). Historia de la Patagonia. Buenos Aires: Ciudad Argentina.

No cesan los derrames de petróleo. (28 de octubre, 2009). Rio Negro. Recuperado de http://wwwl .rionegro.com.ar/diario/2009/10/28/1256699645162. php

ÑIriHuAU: EXPLOTACIÓN DE Hidrocarburos y CONFLICTO SOCIAL EN LAS INMEDIACIONES DE BARILOCHE
No habrá minería ni extracción de petróleo en la zona de Bariloche ( 5 de abril, 2012). Rio Negro. Recuperado de http://www.rionegro.com.ar/diario/ no-habra-mineria-ni-extraccion-de-petroleo-en-la-zona-de-bariloche-849117 -9701-nota.aspx

Observatorio Petrolero Sur. (26 de julio, 2012). Pronunciamiento de los trabajadores del Parque Nacional Calilegua respecto a la explotación petrolera que se desarrolla en dominio y jurisdicción del área protegida. Recuperado de http://www. opsur.org.ar/blog/2012/07/26/ pronunciamientodelostrabajadoresdelparquenacional-calilegua-respecto-ala-explotacion-petrolera-que-se-desarrolla-en-dominio-y-jurisdiccion-del-area-protegida/

Observatorio Petrolero Sur. (2009). Panorama rionegrino: hidrocarburos. Recuperado de http://opsur.files.wordpress. com/2009/09/panorama-rionegrinopdfl.pdf

Parques en alerta por la exploración petrolera. (28 de febrero, 2008). Rio $\mathrm{Ne}$ gro. Recuperado de http://wwwl. rionegro.com.ar/diario/2008/02 /28/20082r28s20.php

Pérez Roig, D, Di Risio, D., y Gil Navarro, M. (2012). Apuntes para una discusión de la soberanía energética en Argentina. Debates urgentes, 1(2), 33-58.

Piotto, A. (3 de enero de 2002). Emanaciones tóxicas en polo petroquímico. A 30 cuadras del Obelisco, una zona con raros olores químicos. Clarín. Recu-

territarias 30

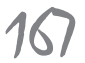


perado de http://edant.clarin.com/ diario/2002/01/03/s-03801.htm

Piqueras, A. (2002). Movimientos sociales y capitalismo. Historia de una mutua influencia. Valencia: Editorial Germaia.

Radovich, J. C. (diciembre, 1992). Política indígena y movimientos étnicos: el caso mapuche. Cuadernos de Antropología, (4), 47-65.

Radovich, J. C. (2002). Conflictos étnicos en la sociedad contemporánea. Cuadernos de Antropologia Social, (16). Recuperado de http://ica.institutos.filo.uba.ar/ seanso/?mod=num_16

Roze, J. y A. Pratesi. (2005). Conflictos centrales en la periferia de la globalización. Buenos Aires-México: Libros en Red.

Salas, H. (2007). Centenario del petróleo argentino 1907-2007. Buenos Aires: IAPG.

Sánchez, G. (2006). La Patagonia vendida. Los nuevos dueños de la tierra. Buenos Aires: Marea Editorial.

Secretaría de Energía de la Nación. (s. f.). Producción de petróleo y gas (tablas dinámicas). Recuperado de http://www. energia.gov.ar/contenidos/verpagina. php? idpagina $=3299$

Seoane, J. (comp.). (2003). Movimientos sociales y conflicto en América Latina. Buenos Aires: Clacso.

Subsecretaría de Medios y Comunicación Pública de Chubut. (2011). Cinco empresas de primer nivel manifestaron interés en las nuevas áreas petroleras licitadas por Chubut, 2 de marzo de 2011. Recuperado de http://noticias.chubut. gov.ar/blog/2011/03/02/cinco-empresas-de-primer-nivel-manifestaroninteres-en-las-nuevas-areas-petroleraslicitadas-por-chubut/

Tarrow, S. (1997). El poder en movimiento. Los movimientos sociales, la acción colectiva y la politica. Madrid: Alianza Universidad.

Touraine, A. (1999). ¿Nuevos movimientos sociales? En ¿Cómo salir del liberalismo? (53-80). México, D. F.: Paidós.

Un manantial de petróleo pone en aprietos el paraíso del Ñrihuau. (15 de junio, 2008). Rio Negro. Recuperado de http://wwwl.rionegro.com.ar/diario/debates/2008/06/15/13308. php

Valverde, S. (2004). Los movimientos indigenas en la Argentina. Las estrategias politicas de las organizaciones mapuches. Buenos Aires: Editorial Universidad de Lanús.

Walther, J. C. (1976). La conquista del desierto. Lucha de frontera con el indio. Buenos Aires: Eudeba.

Worrall, S. (January, 2004). Land of the living wind. National Geographic Magazine. Recuperado de http://ngm. nationalgeographic.com/print/features/world/south-america/argentina/ wind-text

YPF. (2012). Estrategia de gestión 2013-2017. Recuperado de http://www.enerclub. com.ar/upload/archivos/YPF_PLAN_ ESTRATEGICO_127.pdf

Guido Galafassi, Diego Pérez Roig 


\section{Agencias oficiales consultadas}

Administración de Parques Nacionales

Concejo Municipal de San Carlos de Bariloche

Defensoría del Pueblo de la Provincia de Río Negro

Iniciativa Reserva Biósfera Andino Norpatagónica
Legislatura de la Provincia de Río Negro Ministerio de Economía de la Nación

Secretaría de Comunicación de la Provincia de Río Negro

Secretaría de Energía de la Nación

Secretaría de Minería e Hidrocarburos de la Provincia de Río Negro

us Energy Information Administration 
